\title{
COHERENT NOISE ATTENUATION USING THE WAVELET TRANSFORM ON RADIAL BASIS
}

\author{
Lucas José Andrade de Almeida ${ }^{1}$, Rafael Rodrigues Manenti² and Milton J. Porsani²
}

\begin{abstract}
Radial transform rearranges amplitudes of seismic data, from distance-time domain to angle-time domain. Linear events in distance-time domain tend to be sampled as a vertical event in angle-time domain, while seismic reflections maintain its original shape. Wavelet transform decomposes seismic data into sub-bands which capture seismic events oriented in specific directions. Therefore, it provides an excellent framework for ground roll and swell noise segregation. For vertical events, like ground roll, are isolated from horizontal events (reflections). This paper proposes a technique based on the joint implementation of wavelet and radial transforms, taking advantage of both of them as to suppress coherent noise efficiently while preserving reflections. Results in form of shot-gathers, stacked sections and frequency spectra attest the technique's quality and limitations for coherent noise attenuation.
\end{abstract}

Keywords: reflection seismic, noise attenuation, signal processing, multiresolution analysis.

RESUMO. A transformada radial faz um remapeamento das amplitudes do dado sísmico do domínio espaço tempo para o domínio ângulo-tempo. Eventos lineares no primeiro domínio tendem a ser amostrados como eventos verticais no domínio ângulo-tempo, enquanto as reflexões sísmicas mantém sua forma original. A transformada wavelet decompõe 0 dado sísmico original em diferentes sub-bandas, que capturam eventos sísmicos orientados em direções específicas. Portanto, ela provê um excelente domínio para a segregação do ground rol/ e swell noise, visto que eventos verticais, como este, são isolados dos eventos horizontais (reflexões). Este trabalho propõe uma técnica baseada em uma implementação conjunta destas duas transformadas, utilizando suas vantagens de modo a suprimir o ruído coerente eficientemente enquanto preserva as reflexões de interesse. Resultados expressos através de seções de tiro comum, seções empilhadas e espectros de frequência atestam a qualidade da técnica proposta para a atenuação de ruídos coerentes.

Palavras-chave: sísmica de reflexão, atenuação de ruídos, processamento de sinais, análise de multirresolução.

\footnotetext{
${ }^{1}$ Colorado School of Mines, Center of Wave Phenomena, 1500 Illinois St., Golden, C0, United States of America - E-mail: Ikandrade98@gmail.com

2Universidade Federal da Bahia, Centro de Pesquisa em Geofísica e Geologia, Instituto de Geociências, Campus Universitário da Federação, Salvador, BA, Brazil -E-mails: rrmanenti@gmail.com; porsani@cpgg.ufba.br
} 


\section{INTRODUCTION}

Noise can be found virtually in every seismic section, and it can occur due to several factors, such as background, receiver malfunction or even natural conditions, usually classified in two types: random noise, which occurs with no pattern, and coherent noise, which has a set pattern. Seismic noise lowers data's signal-to-noise ratio, impairing several seismic processing workflow steps, such as velocity analysis (Yilmaz, 2001). While random noise is generally simple to attenuate, often through a bandpass filter, coherent noise may prove itself to be very resilient to those, in which case it's necessary to use other techniques to achieve this goal.

Coherent seismic noise attenuation, specially ground roll and swell noise, has been a present topic in most of seismic processing research for a long time, and several methods were proposed to achieve this purpose. In special, methods using Fourier transform are traditional. Those include $\mathrm{f}-\mathrm{k}$ filtering, windowed f-k filtering, frequency filtering, among others (Yilmaz, 2001). Although somewhat efficient, those methods also require fine-tuning to specific dataset and produce artifacts in solution (Askari \& Siahkoohi, 2008).

Radial transform changes seismic data from distance-time domain (XT) to angle-time domain (RT), making linear events show as vertical events, and conserving horizontal events (Henley, 1999). This property renders radial transform useful for events separation, for example, upgoing and downgoing wavefields (Ottolini, 1979) Radial transform can also be useful in case of coherent noise attenuation. For instance, in the RT domain, ground roll appears as a straight vertical event, placed in a smaller band in the middle of the image, making filtering more effective. Manenti \& Porsani (2013) observes that it's not necessary to apply normal moveout correction before noise attenuated while in RT domain, even in methods that rely in adjacent traces horizontal coherence, such as Singular Value Decomposition (SVD).

Wavelet transform, as shown in Almeida \& Porsani (2013) and Matos \& Osorio (2002) has already been used for ground roll attenuation, to decompose data in different sub-bands events in specific orientations, effectively segregating ground roll from reflections. However, in order to preserve shallow reflections in data, it's necessary to apply wavelet transform after normal moveout correction (Almeida \& Porsani, 2013).

This paper proposes a method based on implementation of both transforms, taking advantage of their unique properties to build a multiresolution scheme that is suitable for coherent noise attenuation on most data types and does not possess most of techniques limitations based on Fourier transform, such as artifacts. Experimental results in field data show the method effectiveness in attenuating coherent noise.

\section{RADIAL TRANSFORM}

Radial transform is a simple seismic data amplitude rearrangement (denoted as $S(x, t)$ ), usually placed in distance-time domain (XT), to angle-time or velocity-time domain (RT). This method requires a focus, with coordinate $\left(x_{0}, t_{0}\right)$, which will be the RT angle's origin. This process can be described as Equation 1 (Henley, 1999).

$$
\begin{gathered}
R\{S(x, t)\}= \\
\left(v, t^{\prime}\right) \rightarrow R^{-1}\left\{S^{\prime}(v, t)\right\}=S(x, t) .
\end{gathered}
$$

Parameters $t_{0}$ and $v$ are described as equations 2 as:

$$
\begin{array}{r}
t^{\prime}=t-t_{0} \\
v=\frac{\left(x-x_{0}\right)}{\left(t-t_{0}\right)} .
\end{array}
$$

Although the focus can be placed anywhere in seismogram, usually it's best placed on data's virtual source. Figure 1 shows an example of focus placement in a seismic shot-gather using splitspread geometry and radial traces radiating from it. The number of radial traces in angle-time domain is arbitrary, although it's common sense more radial traces leads to better sampling in angle-time domain.

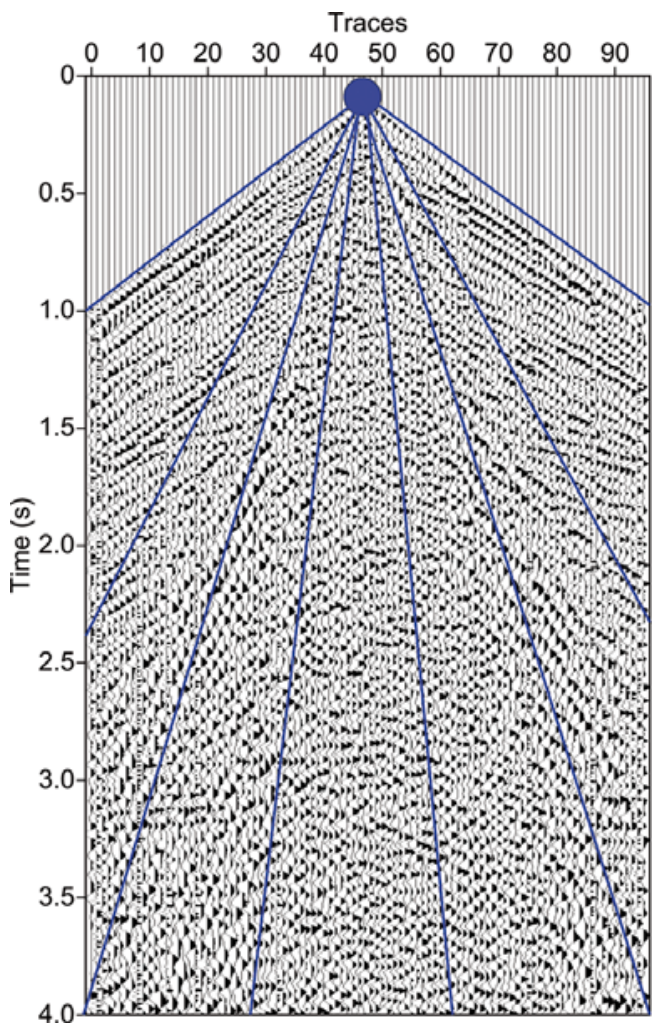

Figure 1 - Representation of the focus at the virtual source point of a seismic shot-gather with radial traces irradiating from it. 
For rearranging data amplitudes along radial traces, some sort of interpolation is necessary. Manenti \& Porsani (2013) use Shepard interpolation with $p=2$ (Shepard, 1968), described in Equation 3,

$$
\tilde{A}=w_{1} A_{1}+w_{2} A_{2},
$$

where $\tilde{A}$ is interpolated amplitude. This interpolation is fairly easy to implement and has a low computational cost. In our experiments, it's sufficient to obtain forward and inverse radial transforms with minimal signal loss. Weights $w_{1}$ and $w_{2}$ are determined by Equation 4

$$
w_{i}=\frac{d_{i}^{-2}}{d_{1}^{-2}+d_{2}^{-2}},
$$

where $d_{1}$ and $d_{2}$ are distance from desired position to sample, along offset axis.

\section{WAVELET TRANSFORM}

Wavelet transform (WT) uses compactly supported functions, denominated wavelets, in order to represent a given signal. A wavelet basis is defined as in Equation 5, where $a$ and $b$ are called dilation and translation coefficients, respectively.

$$
\psi(a, b)=\frac{1}{\sqrt{a}} \psi\left(\frac{t-b}{a}\right) .
$$

By making wavelet dilate or contract, wavelet transform allows one to observe the signal at multiple resolution windows (Daubechies, 1992). Wavelet transform result, or wavelet coefficients for each pair $(a, b)$, is defined as inner product of wavelet basis modified by the pair $(a, b)$ and the given signal, as in Equation 6.

$$
c(a, b)=\langle f(t) \mid \psi(a, b)\rangle=\int_{-\infty}^{\infty} f(t) \psi(a, b) d t .
$$

Because of parameters $a$ and $b$, wavelet analysis differs significantly from conventional Fourier analysis. For instance, shorttime Fourier transform (Cohen, 1989) uses a fixed size window to analyze the whole data, while wavelet transform uses multiple windows of different sizes. This approach makes it more suitable to represent and analyze non-stationary signals, such as seismic traces. Figure 2 illustrates this concept showing the ideal resolution for both transforms.

In its discrete bidimensional form, wavelet transform can be implemented using two different approaches: filter banks (Mallat, 1989) or lifting scheme (Sweldens, 1995). In this work, a filter bank composed by a low-pass and a high-pass filter is used in order to decompose an image into various levels, according to Multiresolution Analysis (Mallat, 1989). The general workflow for wavelet transform is shown in Figure 3. Decomposition procedure involves convolution between filters and signal in both dimensions followed by a downsampling operation, and is iterated on image resulted from low-pass filter. To obtain the reconstructed signal, it's sufficient to reverse the flow, using the appropriate filters.

Figure 4 reveals wavelet transform results, according to workflow in Figure 3. Each level of decomposition contains four sub-bands, which captures different coefficients orientations and frequencies, which depend on the combination of filters used to produce the sub-band (Cohen \& Chen, 1993).

\section{METHODOLOGY}

As seen in Almeida \& Porsani (2013) for effective ground roll suppression, it's necessary to apply NMO correction prior to wavelet transform decomposition, in order to preserve shallower reflections. However, this is not an ideal scenario for noise filtering, as a proper NMO correction needs an accurate velocity estimation, which may not be available. In this work, we rely on radial transform to rearrange data amplitudes so it's possible to turn all linear events into vertical events. This allows us to restrain them to a very narrow band in the middle of angle-time domain. Therefore, wavelet transform works more effectively, better separating noise from signal of interest. In general, our approach uses the following steps:

- Apply forward radial transform to the data;

- Apply forward wavelet transform to the data;

- Identify and suppress vertical sub-band resulted from wavelet transform;

- Apply inverse wavelet transform;

- Apply inverse radial transform.

In the following sections, these steps will be used to show some examples of noise attenuation schemes.

\section{Ground Roll Attenuation}

The proposed method was tested using land-based seismic data from Tacutu basin, located in the North of Brazil. It contains 179 shots recorded in 1001 samples at 4 ms sampling interval. Each shot has 96 channels, in a split-spread geometry with offsets from $-2500 \mathrm{~m}$ to $2500 \mathrm{~m}$ and a $50 \mathrm{~m}$ spacing between geophones. 


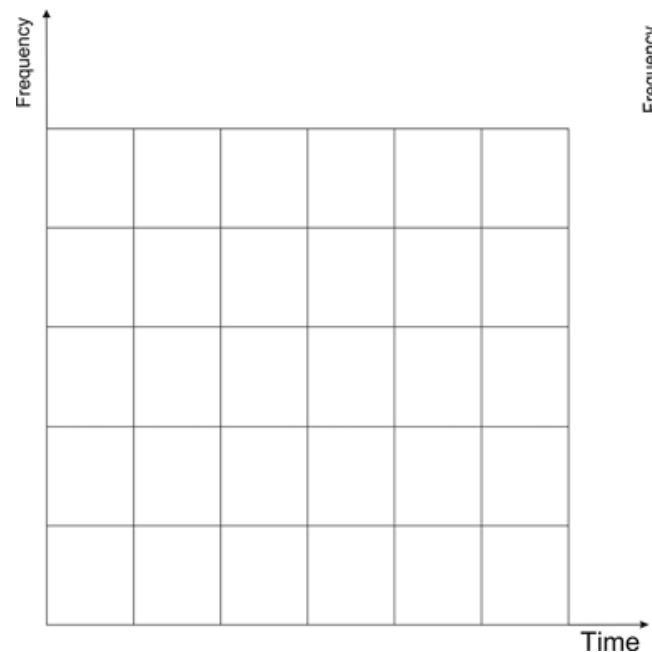

(a)

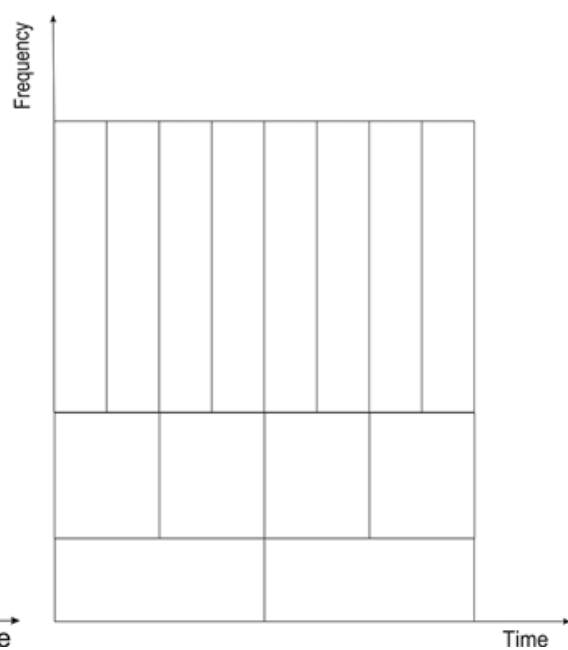

(b)

Figure 2 - (a) - Time-frequency resolution of the short-time Fourier transform. (b) - Time-frequency resolution of the wavelet transform.

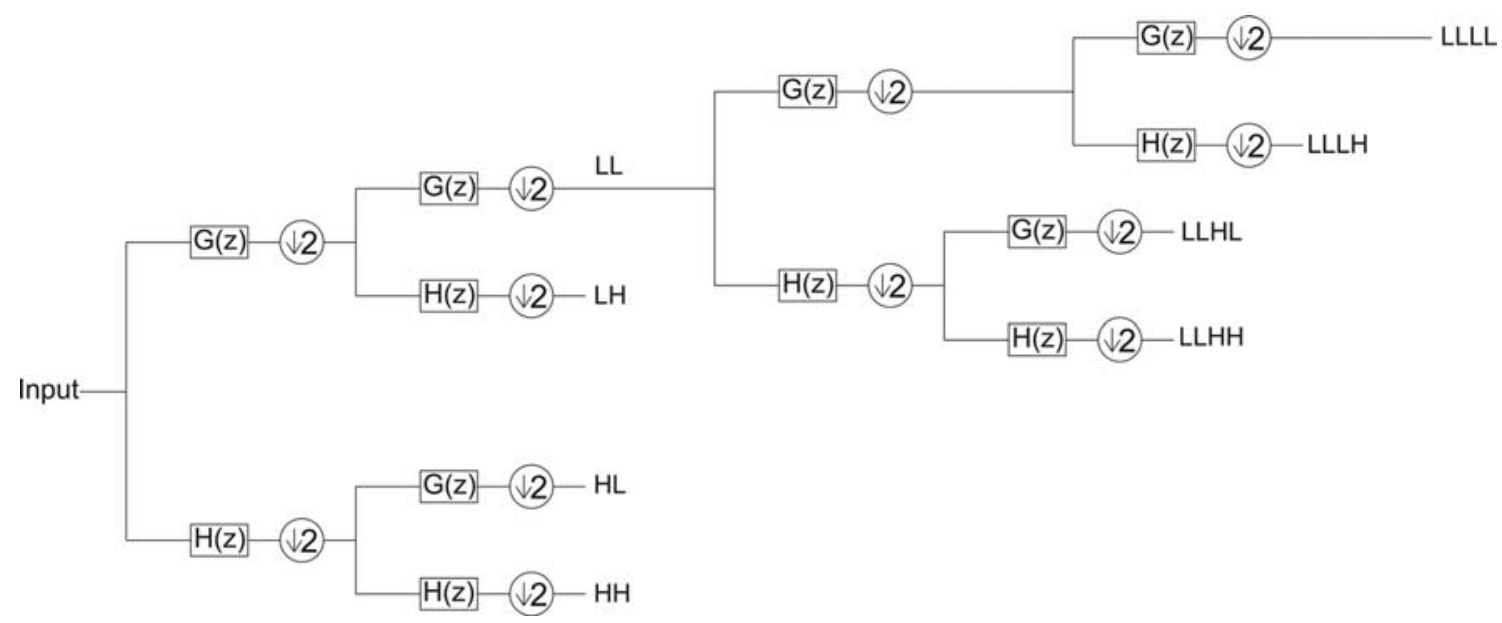

Figure 3 - Flow for implementing the forward wavelet transform. $G(Z)$ and $H(Z)$ represent the low-pass $(L)$ and high-pass $(H)$ filters, respectively.

The acquisition has shots interval of $200 \mathrm{~m}$ and a CMP coverage of 12 fold

After data pre-processing (geometry, mute and remove noisy traces), we follow the proposed steps for noise filtering. Then, NMO correction followed by conventional stacking. Due to data's Iow CMP coverage, supergathers are used to improve velocity analysis and ensure a better velocity function is picked.

It's pertinent to address wavelet and radial transforms parameters used in this application. For the radial transform, the focus is placed in the shot-gather's virtual source. It was used an angle aperture between 77 and 102 degrees and a discretization of 500 radial traces in angle-time domain, which means that data is interpolated to 500 traces. For wavelet transform, wavelet Symlet- 6 was used, whose filter bank can be obtained in Da Silva (2008). We perform wavelet transform using three levels of decomposition, and vertical sub-band is zeroed in each of those.

\section{Swell Noise Attenuation}

It's straightforward to also test our approach on swell noise contaminated data, because of its similarity with ground roll noise. The procedure for noise attenuation is carried in a similar way as for ground roll attenuation, changing only radial transform parameters. We use 1800 radial traces and an angle aperture between 


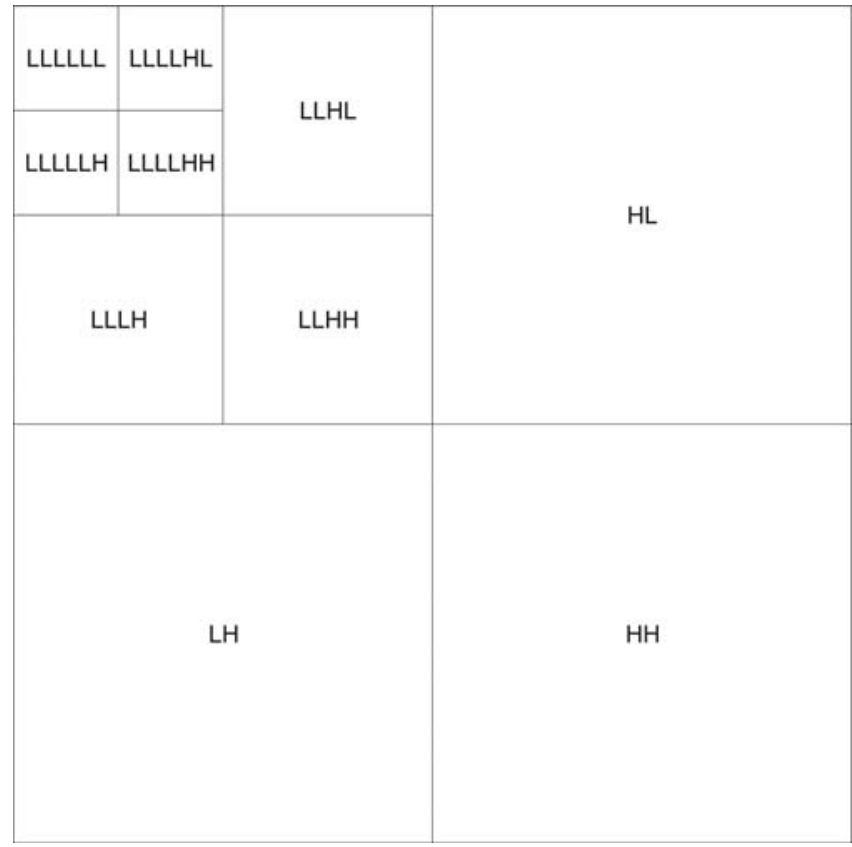

Figure 4 - Wavelet transform sub-bands for a three-level decomposition, according to Figure 3.

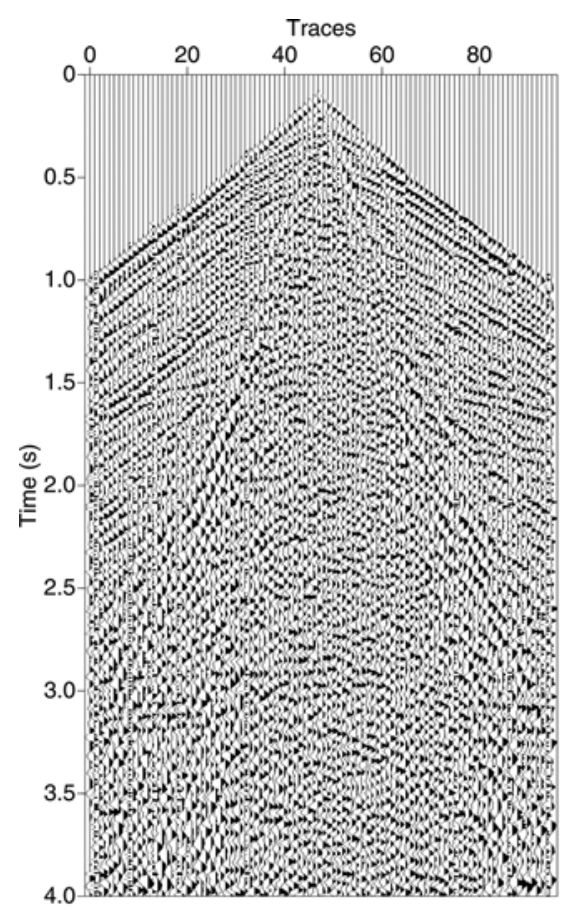

(a)

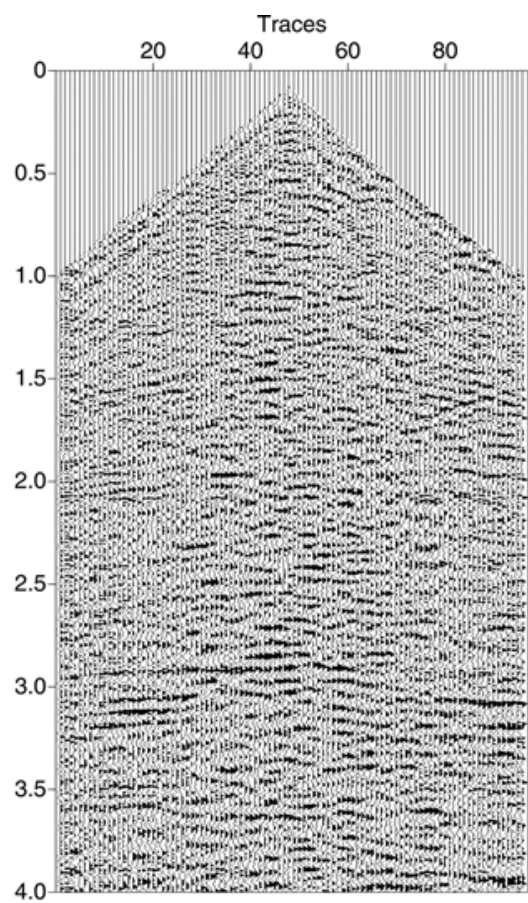

(b)

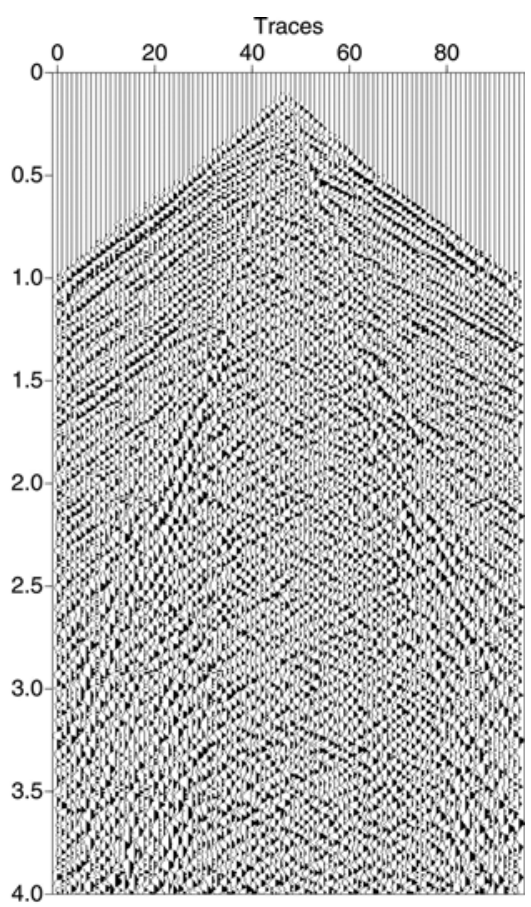

(c)

Figure $\mathbf{5}$ - Results of filtering using only the wavelet transform: (a) - Original shot-gather. (b) - Filtered shot-gather. (c) - Difference shot-gather. 


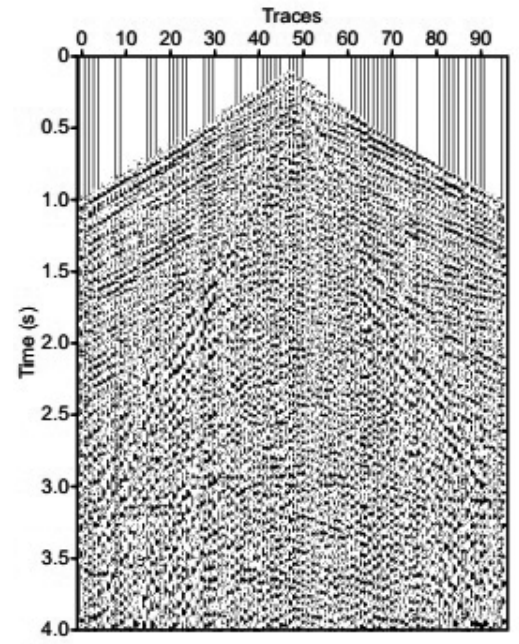

(a)

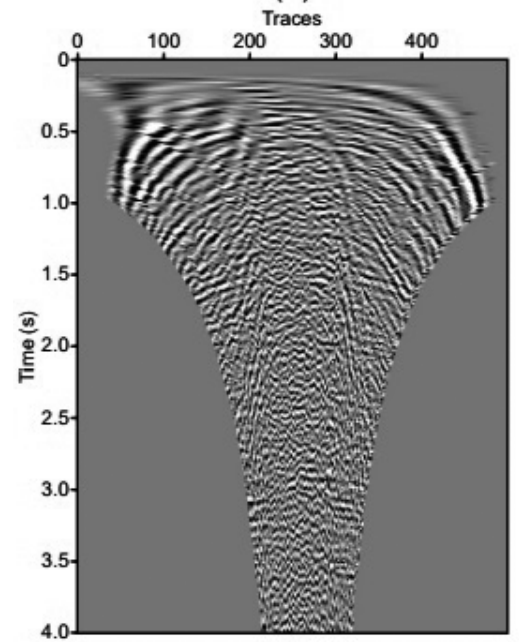

(c)

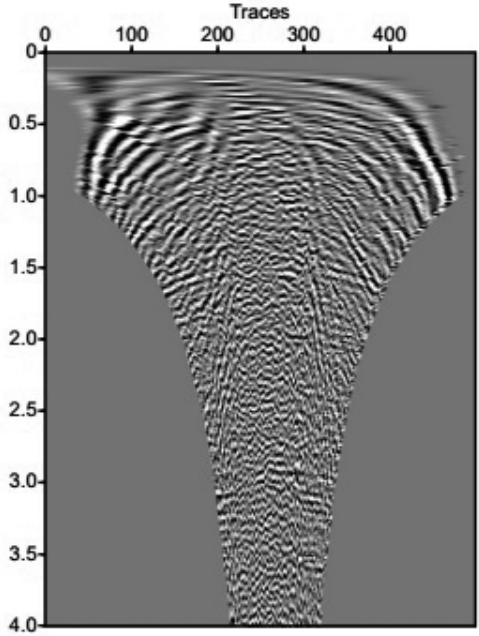

(b)

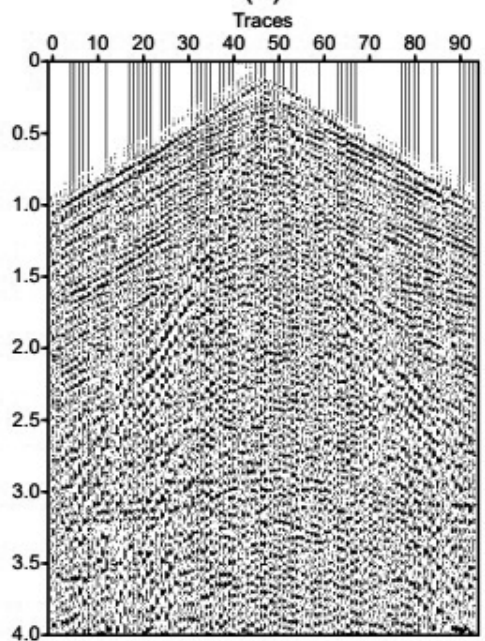

(d)

Figure $\mathbf{6}$ - Reconstruction fidelity: (a) - Original shot-gather. (b) - Shot-gather after the forward radial transform. (c) - Shot-gather after the inverse wavelet transform. (d) - Reconstructed shot-gather.

53 and 90 degrees due to the greater number of time samples in this shot-gather. Also, the transform focus is placed in the shotgather origin.

\section{RESULTS}

Reconstruction fidelity was tested in our proposed approach. Figure 5 shows original and reconstructed shot-gathers, along with original shot-gather in radial domain and after reconstruction. The reconstruction is successful, and there is no meaningful difference between original and reconstructed data.

We use the same data for ground roll attenuation experiment. Figure 6 shows four sub-bands associated with wavelet first level decomposition. Note that wavelet transform is applied to shot- gather in radial domain, shown in Figure 5(b). Ground roll is mostly present in vertical sub-band, effectively separating ground roll from seismic reflections. In Figure 7, Frequency spectra of four bands shows that vertical sub-band contains a significant portion of low frequency, which is associated with ground roll noise.

Figure 8 shows the reconstruction result after vertical subband is zeroed, along with difference between it and original seismic shot-gather. Ground roll noise is, in fact, attenuated, although some of it resisted at shallow part of shot-gather. The frequency spectrum of filtered shot-gather, shown in 9, also indicates that ground roll is attenuated due to a lower content of low frequencies. The proposed method's efficiency can also be confirmed through 


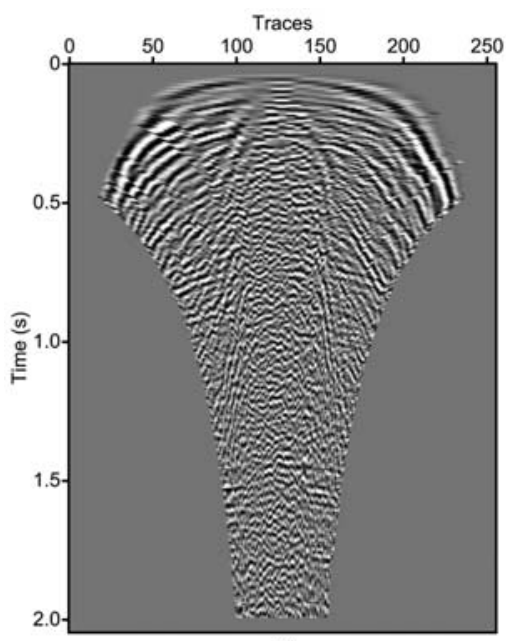

(a)

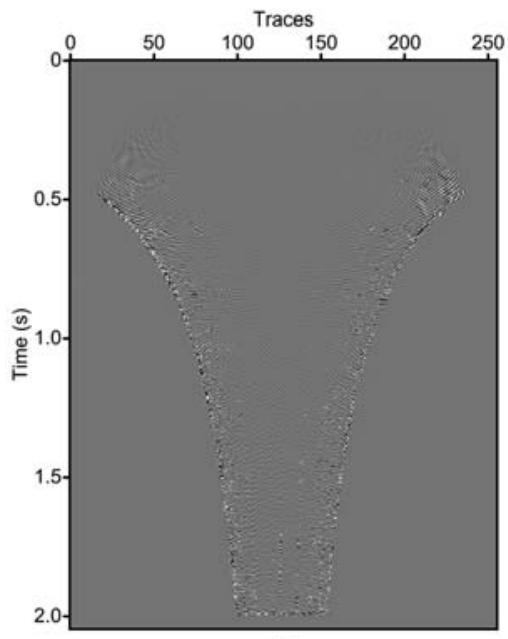

(c)

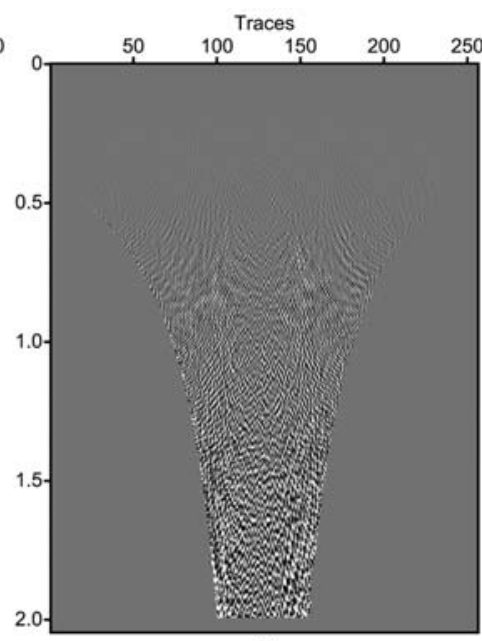

(b)

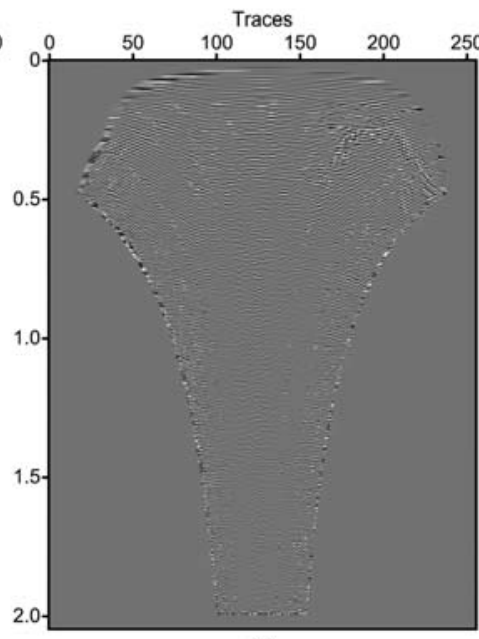

(d)

Figure 7 - Wavelet transform sub-bands for land shot-gather: (a) - Softened sub-band. (b) - Vertical sub-band. (c) - Diagonal sub-band. (d) - Horizontal sub-band.

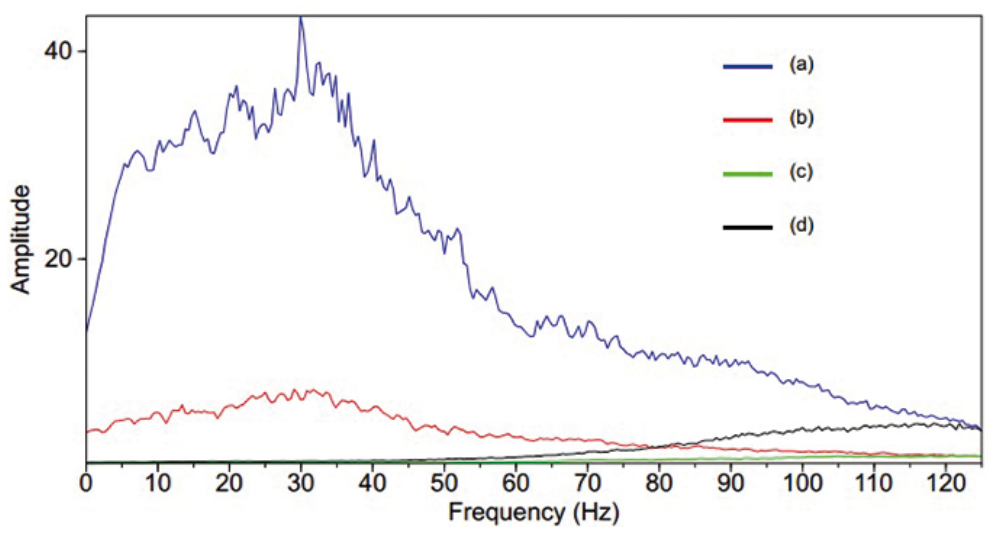

Figure 8 - Frequency spectrum of Figure 6: (a) - Softened sub-band. (b) - Vertical sub-band. (c) - Diagonal sub-band. (d) - Horizontal sub-band. 


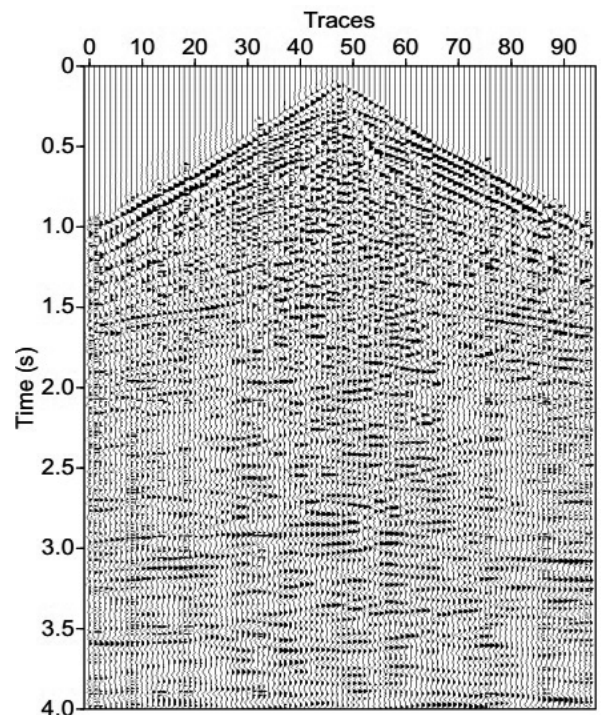

(a)

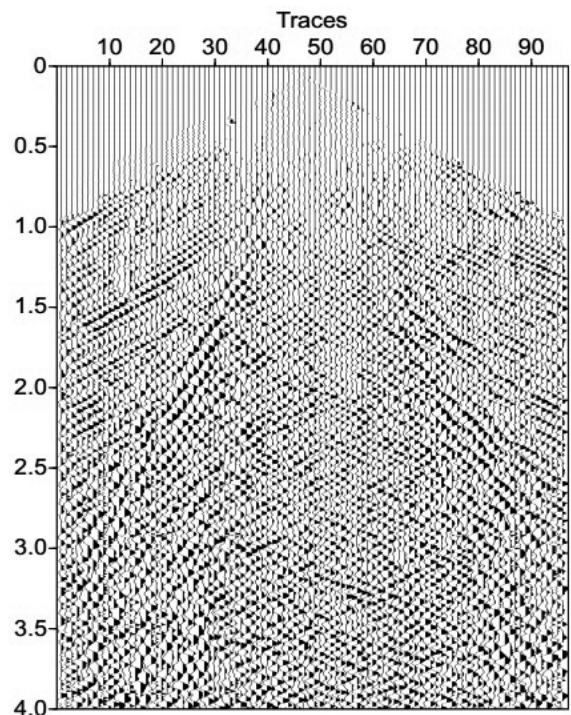

(b)

Figure $\mathbf{9}$ - (a) - Filtered shot-gather. (b) - Difference between original and filtered shot-gathers.

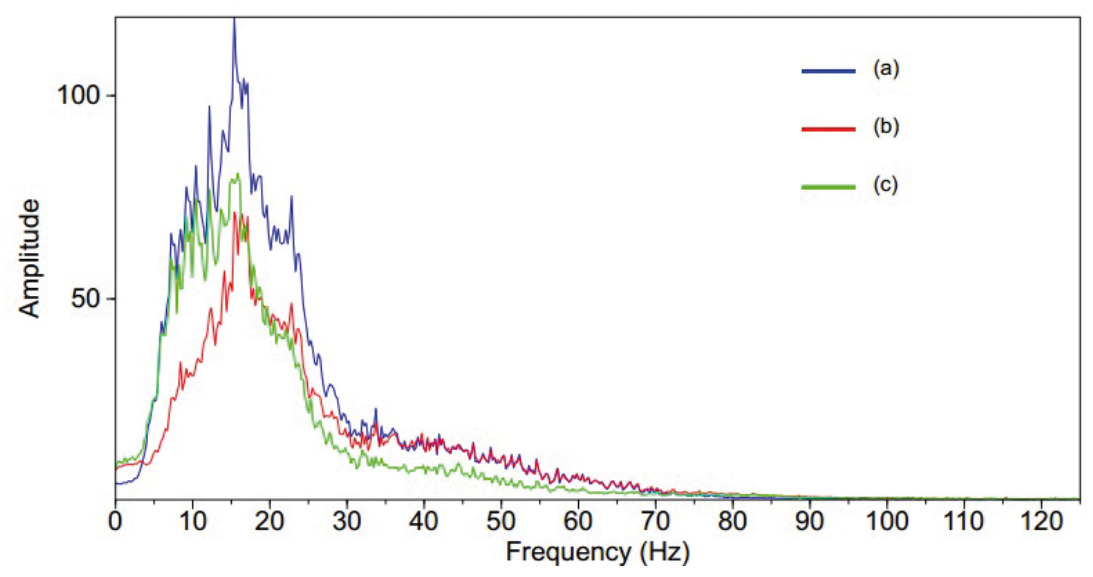

Figure 10 - Frequency spectrum of Figure 8. (a) - Original shot-gather. (b) - Filtered shot-gather. (c) - Difference shot-gather.

Figures 10 and 11, which features original and filtered stacked sections, respectively.

Swell-noise application also shows satisfactory results. Original shot-gather can be seen in Figure 13(a), while four sub-bands associated with first level of the wavelet transform are shown in Figure 14. As expected, most of swell noise is presented inside the vertical sub-band. Figure 13(b) presents reconstructed shot-gather, where swell noise is effectively attenuated. Frequency spectra displayed in Figure 15 shows low frequency content in filtered shot-gather is lower than in original shot-gather, also signaling the swell noise suppression.

\section{CONCLUSIONS}

The joint application of radial and wavelet transforms proved to be an interesting technique for filtering coherent noise, such as ground roll. Overall, results obtained from the usage of this technique on Tacutu basin data and on swell noise contaminated shot-gather had equivalent response with most of the ongoing ground roll filtering techniques, with its low computational cost as a major positive factor, considering that we used two transforms. Other possible application would be random noise attenuation, which could further consolidate the technique as a viable option. We leave this application for future work. 


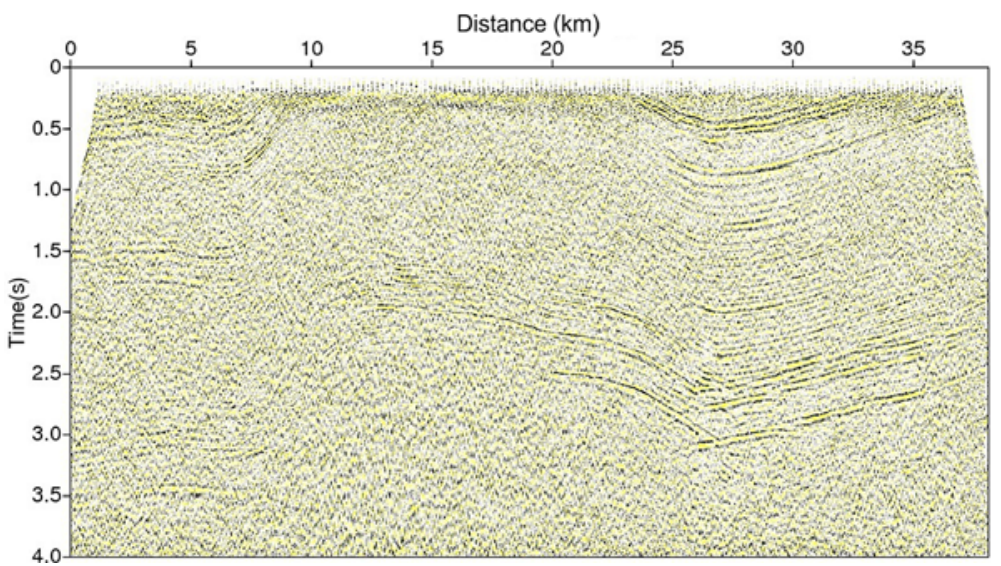

Figure 11 - (a) - Original stacked section.

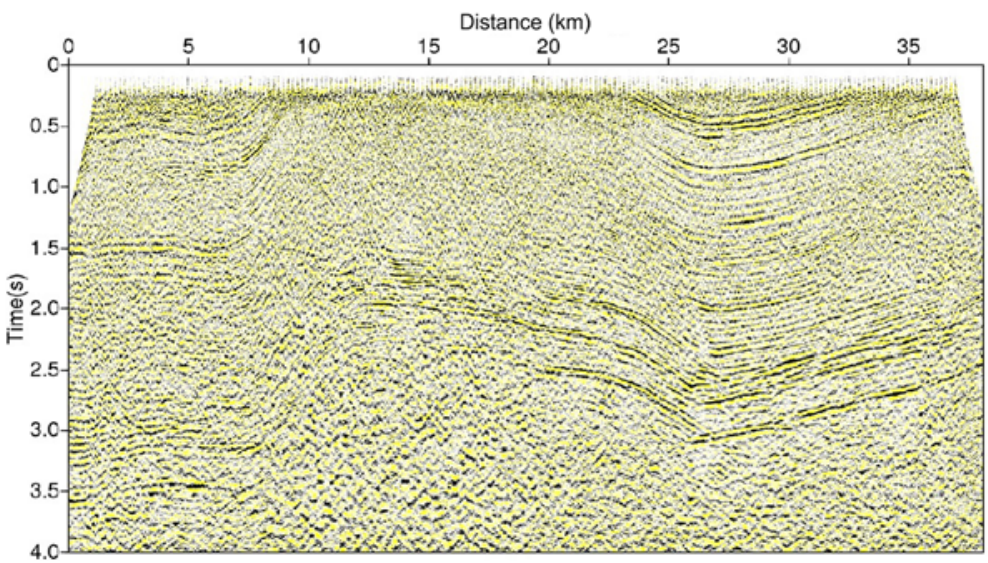

Figure 12 - (a) - Filtered stacked section using the method proposed in this work.

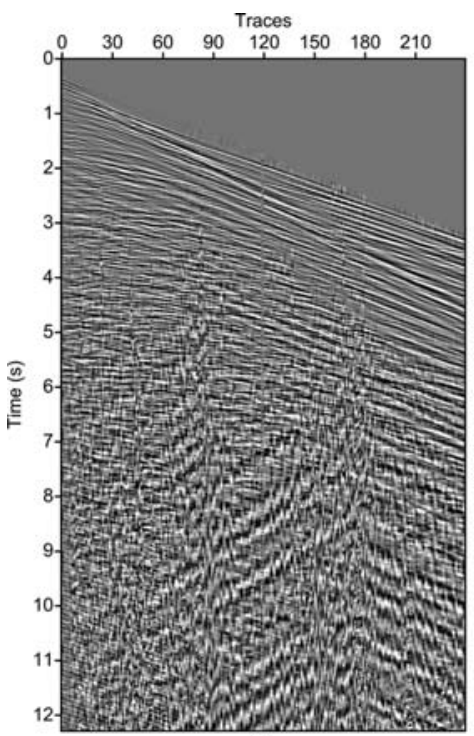

(a)

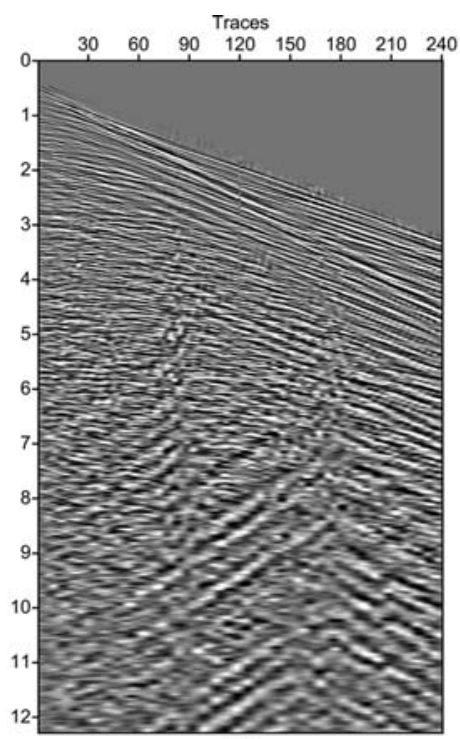

(b)

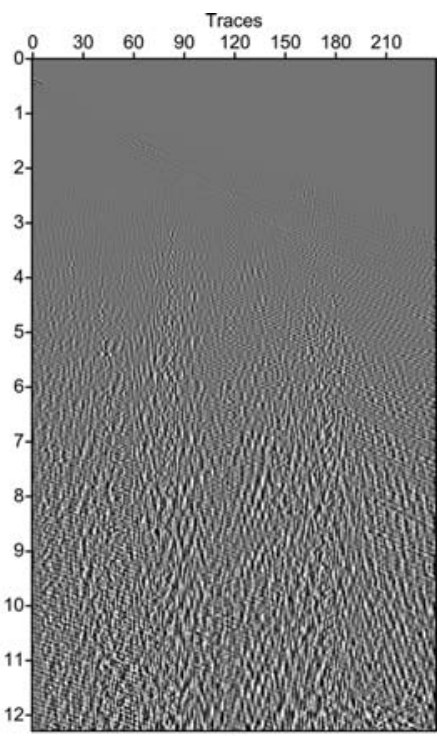

(c)

Figure 13 - (a) - Original shot-gather. (b) - Filtered shot-gather. (c) - Difference shot-gather. 


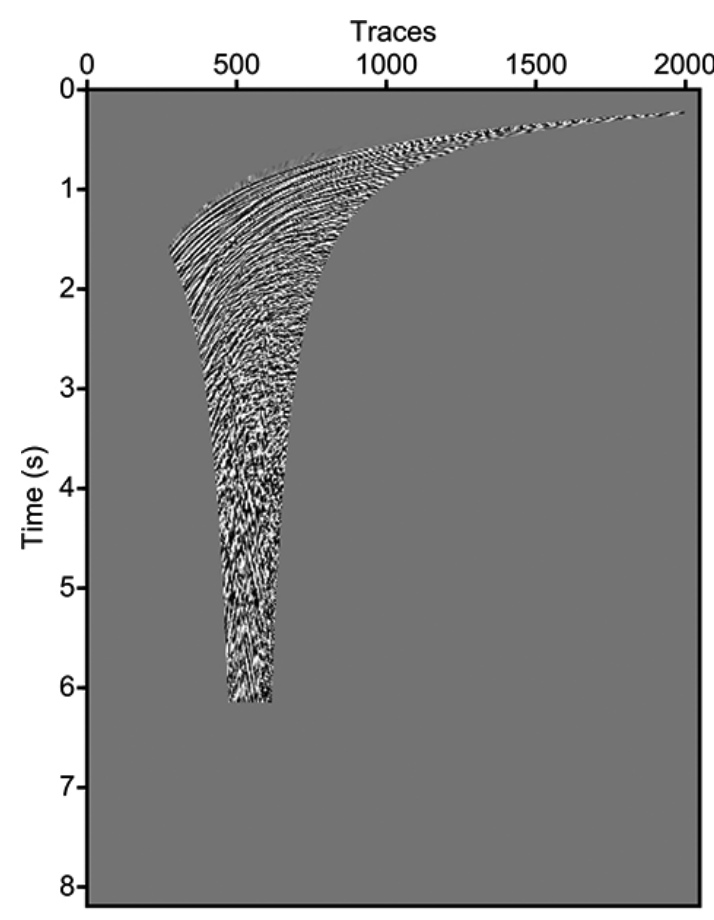

(a)

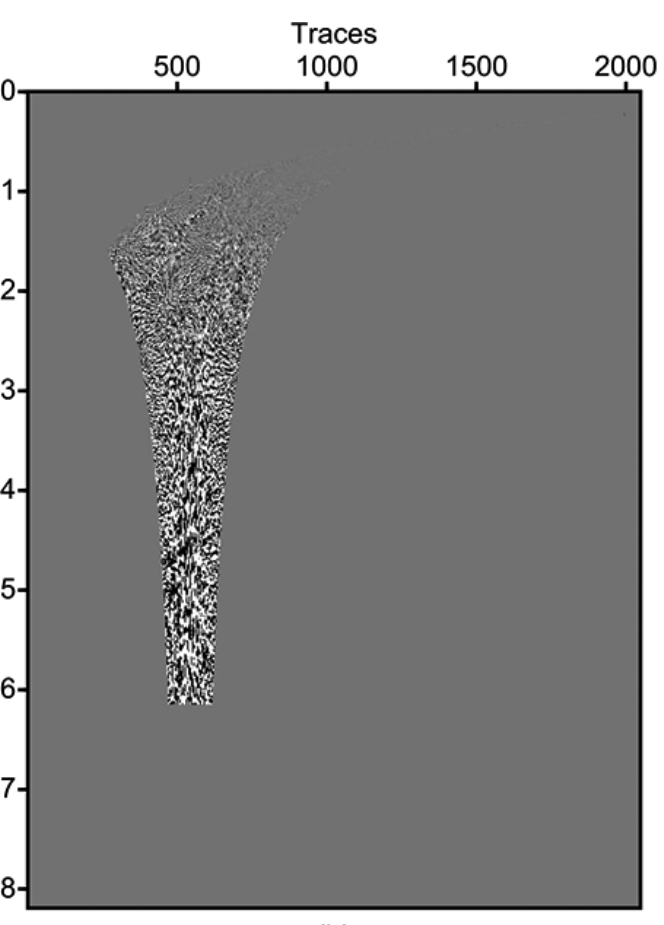

(b)

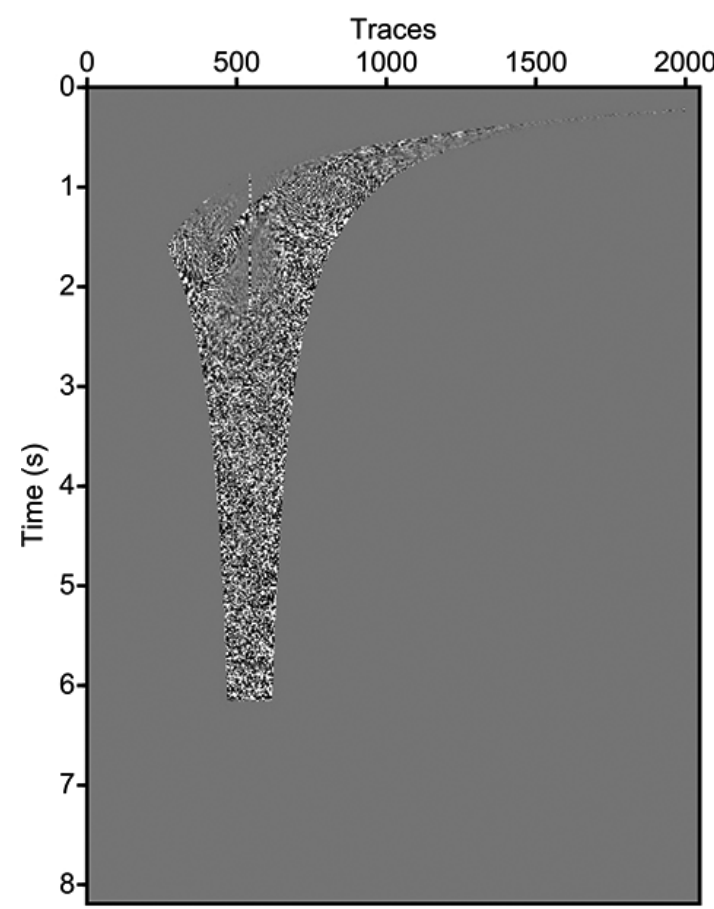

(c)

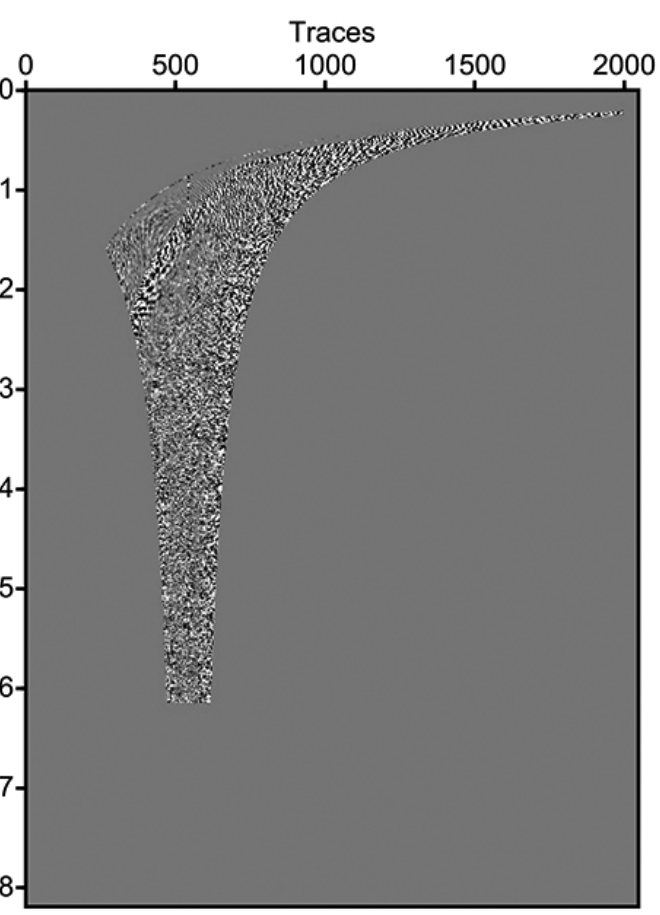

(d)

Figure 14 - Wavelet transform sub-bands for marine shot-gather: (a) - Softened sub-band. (b) - Vertical sub-band. (c) - Diagonal sub-band. (d) - Horizontal sub-band. 


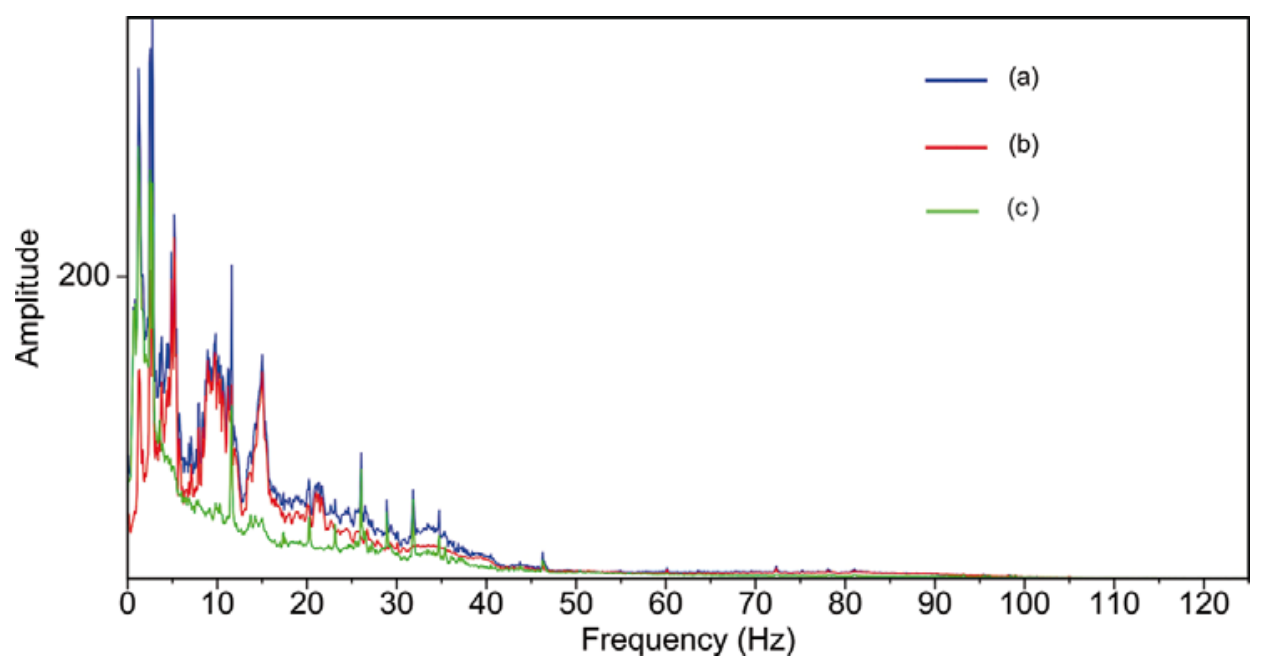

Figure 15 - Frequency spectrum of Figure 13: (a) - Original shot-gather. (b) - Filtered shot-gather. (c) - Difference shot-gather.

One of the possible limitations of the technique is low quantity of radial traces that can be used in the radial transform part of the technique. The radial traces amount control the fidelity of seismic data representation in angle-time domain, and it should be used in direct proportion to duration of acquisition, or time samples number in a shot-gather. Unfortunately, it wasn't possible to apply the technique with success using more than 500 radial traces in the ground roll example and 1800 radial traces on the swell noise example, which we consider to be a low number for the amount of time samples in each of those shot-gathers. This could greatly impair the application of this method in sections bearing large acquisition times, specially in marine data. Our current effort is to overcome this limitation, as to make this technique more robust and applicable on sections with any number or time samples.

\section{ACKNOWLEDGEMENTS}

The authors wish to express their gratitude to CAPES, INCTGP/CNPq/MCT, PETROBRAS, ANP, FINEP, BP Energy do Brasil (PABIP Project) and FAPESB Brazil for financial support. The authors also thank LANDMARK for the licenses granted to CPGG/IGEO/UFBA.

\section{REFERENCES}

ALMEIDA LJA \& PORSANI MJ. 2013. Noise attenuation technique using the 2D wavelet transform and the adaptive deconvolution on pre-stack and post-stack data. In: Expanded Abstract, 13th International Congress of the Brazilian Geophysical Society, Rio de Janeiro, Brazil. CD-ROM.
ASKARI R \& SIAHKOOHI HR. 2008. Ground roll attenuation using the $S$ and $x-f-k$ transforms. Geophysical Prospecting, 56: 105-114.

COHEN L. 1989. Time-frequency distributions - a review. Proceedings of IEEE, 7(77): 941-981.

COHEN JK \& CHEN T. 1993. Quantitative dip bounds for the twodimensional discrete wavelet transform. Mathematical Methods in Geophysical Imaging, 2033: 140-157.

DA SILVA RD. 2008. Segmentação de imagens baseada em descritores de textura extraídos por transformadas wavelets. Masters Dissertation, Universidade Federal do Paraná, Brazil.

DAUBECHIES I. 1992. Ten lectures on wavelets. SIAM CBMS-NSF Regional Conference Series in Applied Mathematics.

HENLEY DC. 1999. The radial trace transform: an effective domain for coherent noise attenuation and wavefield separation. In: Expanded Abstract, 69th SEG Annual Meeting, 1204-1207.

MALLAT S. 1989. A theory for multiresolution signal decomposition: The wavelet representation. IEEE Transactions on Pattern Analysis and Machine Intelligence, 7: 674-693.

MANENTI RR \& PORSANI MJ. 2013. Ground roll attenuation applying adaptive singular value decomposition method in the radial domain. In: Expanded Abstract, 83th SEG Annual Meeting, 4402-4406.

MATOS MC \& OSORIO PLM. 2002. Wavelet transform filtering in the 1D and 2D for ground roll suppression. In: Expanded Abstract, 72nd SEG Annual Meeting, 2245-2248.

OTTOLINI R. 1979. Migration of radial traces sections. Stanford Exploration Project, Report, SEP-20: 97-115. 
SHEPARD D. 1968. A two-dimensional interpolation function for irregularly spaced data. In: Proceedings of the 23rd Nat. Conf. ACM Brandon/Systems Press Inc., Princeton, 517-523.

SWELDENSW. 1995. The lifting scheme: A new philosophy in biorthog- onal wavelet constructions. Wavelet Applications in Signal and Image Processing III, 68-79.

YILMAZ 0. 2001. Seismic data analysis: processing, inversion and interpretation of seismic data. SEG. 2027 pp.

Recebido em 6 março, 2015 / Aceito em 23 fevereiro, 2017

Received on March 6, 2015 / Accepted on February 23, 2017 